\title{
Two examples of online eHealth platforms for supporting people living with cognitive impairments and their caregivers*
}

\author{
Vassilis Solachidis \\ Information Technologies Institute \\ Centre for Research and Technology \\ Hellas, \\ P.O. Box 60361 \\ Thessaloniki, Greece \\ vsol@iti.gr \\ Konstantinos Votis \\ Information Technologies Institute \\ Centre for Research and Technology \\ Hellas \\ P.O. Box 60361 \\ Thessaloniki, Greece \\ kvotis@iti.gr
}

\author{
Ioannis Paliokas \\ Information Technologies Institute \\ Centre for Research and Technology \\ Hellas, \\ P.O. Box 60361 \\ Thessaloniki, Greece \\ ipaliokas@iti.gr \\ Ulises Cortés \\ Technical University of Catalonia \\ Computer Science Department \\ C/Jordi Girona 1-3 \\ E-08034 \\ Barcelona, Spain \\ ia@cs.upc.edu
}

\author{
Nicholas Vretos \\ Information Technologies Institute \\ Centre for Research and Technology \\ Hellas, \\ P.O. Box 60361 \\ Thessaloniki, Greece \\ vretos@iti.gr \\ Dimitrios Tzovaras \\ Information Technologies Institute \\ Centre for Research and Technology \\ Hellas \\ P.O. Box 60361 \\ Thessaloniki, Greece \\ tzovaras@iti.gr
}

\begin{abstract}
This paper compares two methodological approaches derived from the EU Horizon 2020 funded projects CAREGIVERSPROMMD (C-MMD) ${ }^{1}$ and ICT4LIFE ${ }^{2}$. Both approaches were initiated in 2016 with the ambition to provide new integrated care services to people living with cognitive impairments, including Dementia, Alzheimer and Parkinson disease, as well as to their home caregivers towards a long-term increase in quality of life and autonomy at home. An outline of the disparities and similarities related to non-pharmacological interventions introduced by the two projects to foster treatment adherence was made. Both approaches have developed software solutions, including social platforms, notifications, Serious Games, user monitoring and support services aimed at developing the concepts of self-care, active patients and integrated care. Besides their differences, both projects can be benefited by knowledge and technology exchange, pilot results sharing and possible user's exchange if possible in the near future.
\end{abstract}

\section{CCS CONCEPTS}

- Applied computing $\rightarrow$ Life and medical sciences $\rightarrow$ Health care information systems

\footnotetext{
${ }^{1}$ https://caregiversprommd-project.eu/

http://www.ict4life.eu/

* Publication rights licensed to ACM. ACM acknowledges that this contribution was authored or co-authored by an employee, contractor or affiliate of a national government. As such, the Government retains a nonexclusive, royalty-free right to publish or reproduce this article, or to allow others to do so, for Government purposes only.

PETRA '18, June 26-29, 2018, Corfu, Greece

(C) 2018 Copyright is held by the owner/author(s). Publication rights

licensed to ACM.

ACM ISBN 978-1-4503-6390-7/18/06 ..\$15.00

https://doi.org/10.1145/3197768.3201556
}

\section{KEYWORDS}

Behaviour Change Support Systems, user monitoring, MCI, Alzheimer, Dementia, Parkinson

\section{ACM Reference format:}

V. Solachidis, I. Paliokas, N. Vretos, K. Votis, U. Cortés, D. Tzovaras,. 2018. Two examples of online eHealth platforms for supporting people living with cognitive impairments and their caregivers. In Proceedings of ACM PETRA Conference, Corfu, Greece, June 2018 (PETRA'2018), 6 pages.

\section{INTRODUCTION}

In the light of the increasing interest of people living with cognitive impairments, their caregivers and the medical and social professionals on Information and Communication Technologies (ICT), a new generation of online interventions are proposed for treatment adherence, patient monitoring, education, decision making and support. As it has highlighted by other researchers too, such online platforms can provide cognitive stimulation and maintain communication with personal social networks like family and friends [1]. Apart from distant clinical and communication services, modern eHealth platforms can offer educational materials on health-related issues [2]. Although each eHealth application has unique characteristics, they aim to improve the quality of life of people living with cognitive impairments, to control the care expenses for the affected families, to increase their independence and autonomy at home.

To mention a few examples, VALID (Valuing Active Life in Dementia) [3] is a research project that evaluates community occupational therapy interventions for People Living With Dementia (PLWD) and their family caregivers. RHAPSODY (Research to Access Policies and Strategies for Dementia in the Young) [4] is another EU funded dementia research project which aims to improve care for people with Young Onset Dementia (YOD) by providing an internet-based information and skill- 
building interventions programme for family caregivers through an e-learning platform.

ACTIFCare (ACcess to TImely Formal Care) [5] aims to optimize the care for European citizens with dementia in the middle phase, by identifying best practices and finding the best fit between needs and appropriate access and use of care services.

RAMCIP [6] (Robotic Assistant for Mild Cognitive Impairments (MCI) Patients at home) developed assistive robotics solutions for the elderly and those suffering from MCI and dementia. This project also makes use of serious games and infotainment solutions.

In this paper two EU Horizon 2020 funded projects namely the CAREGIVERSPRO-MMD (C-MMD) and ICT4LIFE, will be discussed and their methodologies will be compared in order to identify common tools and practices. In section 2 both project will be described shortly, while in section 3 the user monitoring process will be presented. Then, in the next section, the used technologies and the system architectures will be compared. Finally, in sections 5 and 6 potentiality of cooperation between the two projects is investigated.

\section{ICT4LIFE AND C-MMD PROJECTS AT A GLANCE}

The C-MMD project develops an online platform targeting primarily to both members of the 'dyad' which is the PLWD and their caregivers. More specifically, caregivers are treated as people at risk too and the C-MMD platform provides help to reduce the level of stress and thus the risk of a burnout. Offered services include social interactions between dyads, clinical and social professionals, as well as interactions between the two members of the dyad.

Another set of services include reminders, information on local resources, health and quality of life monitoring using screening tools (questionnaires) and highly personalized interventions providing educational material and training cognitive abilities at risk for coping with health-related issues. Secondary goals include the delay or reduce of the institutionalization for PLWD.

On the other hand, the ICT4LIFE project is designed for both indoor and outdoor use case scenarios. ICT4Life performs indoors activity recognition through advanced sensing to detect deviations from persons' daily conduct while is provides advanced visual analytics to the professionals for monitoring their patients' health status. In parallel, it continuously monitors the patient's health status using unobtrusive biomedical sensors.

The C-MMD platform is delivered to its users through a web interface for Personal Computers (PCs) which also allows encapsulating the web view in mobile devices, mostly tablets. Similarly to C-MMD, ICT4LIFE is offered to patients and caregivers through mobile/tablet applications for Android but doctors/ professionals gain access using a web interface optimized PCs or tablets.

Moreover, in C-MMD the dyad (PLWD \& caregiver) is considered the unit of care, while ICT4Life is more patientcentric. Both allow authorized caregivers to have access to patients' personal or health information. Table 1 summarizes the similarities and the differences between the two projects under study.

Table 1: Differences and similarities between the two projects C-MMD and ICT4LIFE

\begin{tabular}{|c|c|}
\hline & ICT4Life \\
\hline $\begin{array}{l}\text { Full project } \\
\text { title }\end{array}$ & $\begin{array}{l}\text { ICT4Life services for Life Improvement for } \\
\text { Elderly Horizon } 2020\end{array}$ \\
\hline Vision & $\begin{array}{l}\text { To increase the quality of life and the } \\
\text { autonomy of elders at their own homes, } \\
\text { nursing homes, day care centres and hospitals. }\end{array}$ \\
\hline Entry point & http://www.ict4life.eu \\
\hline Instrument & Tailor made app delivering services \\
\hline $\begin{array}{l}\text { Services in } \\
\text { offer }\end{array}$ & $\begin{array}{l}\text { - Sensorial data acquisition } \\
\text { - Abnormal patient behavior detection } \\
\text { - Advanced notifications subsystem } \\
\text { - Serious Games for brain fit } \\
\text { - User interaction with the system, } \\
\text { monitoring and analysis } \\
\text { - Reporting using visual analytics } \\
\text { (abnormal events, biological } \\
\text { measurements) }\end{array}$ \\
\hline
\end{tabular}

\section{C-MMD}

Self-management interventions and mutual assistance community services, helping patients with dementia and caregivers connect with others for evaluation, support and inspiration to improve the care experience

To extend the independent life of the elderly, with the dual aim of increasing their quality of life and reducing the costs of care.

\section{https://caregiverspro-mmd.eu}

A social networking online platform with peripherals

- Internationalization and localization service

- Social networking services

- Gamification

- Personalized recommendations \& UI adaptation

- User interaction activity logging

- Screening for dementia \& psychiatric comorbidities

- Treatment adherence 


\begin{tabular}{|c|c|c|}
\hline & ICT4Life & C-MMD \\
\hline & $\begin{array}{l}\text { - Education through the platform and the } \\
\text { social network }\end{array}$ & $\begin{array}{l}\text { - } \quad \text { Reporting using visual analytics } \\
\text { - } \quad \text { Non-pharmacological interventions } \\
\text { - } \quad \text { Serious Games for brain fit }\end{array}$ \\
\hline $\begin{array}{l}\text { Data sharing } \\
\text { and } \\
\text { transparency }\end{array}$ & $\begin{array}{l}\text { Web access to authorized professionals } \\
\text { involved in the care of the patients (doctors, } \\
\text { nurses, social workers, physiotherapists, } \\
\text { psychologists, neurologists) as well the non- } \\
\text { professional caregivers (e.g. patient's spouse, } \\
\text { child) }\end{array}$ & $\begin{array}{l}\text { Dyads give permissions to professionals in the C- } \\
\text { MMD ecosystem to access their data }\end{array}$ \\
\hline Users & $\begin{array}{l}\text { For Alzheimer and Parkinson patients as well } \\
\text { as their caregivers and medical professionals }\end{array}$ & $\begin{array}{l}\text { Primarily for Dyads (people living with mild to } \\
\text { moderate dementia and their caregivers), but social } \\
\text { and medical professionals are included in the list of } \\
\text { users }\end{array}$ \\
\hline $\begin{array}{l}\text { Sensing } \\
\text { Technology }\end{array}$ & $\begin{array}{l}\text { Sensors (Kinect cameras, 360o RGB cameras, } \\
\text { smart wrist bands, binary sensors, WSN } \\
\text { sensors), interaction history through log files }\end{array}$ & $\begin{array}{l}\text { e-surveys, online and offline questionnaires, user } \\
\text { interaction history through log files }\end{array}$ \\
\hline Pilot countries & $\begin{array}{l}\text { Be tested in real operating environments, short } \\
\text { pilots ( }<50 \text { users }) \text { in } 2018\end{array}$ & $\begin{array}{l}\text { Be tested in homes and day-care organizations, } \\
\text { large-scale pilots ( } 600 \text { dyads) in } 2018\end{array}$ \\
\hline $\begin{array}{l}\text { Multilanguage } \\
\text { support }\end{array}$ & English, French, Spanish, Hungarian & English, French, Italian, Spanish \\
\hline Design & \multicolumn{2}{|c|}{ User-centric, adaptable to the needs of the different platform users } \\
\hline Privacy & Secure communication channels & Anonymization, secure communication channels \\
\hline Future plans & $\begin{array}{l}\text { To test the platform in a broader number of } \\
\text { groups of users }\end{array}$ & $\begin{array}{l}\text { To prepare for sustainable pan-European rollout of } \\
\text { the platform }\end{array}$ \\
\hline
\end{tabular}

\section{USER'S MONITORING}

Social and clinical screening services in C-MMD are being offered for dyads (PLWD, their caregiver and their dyadic relationship itself). The user distant monitoring service comprise checklists identifying symptoms of dementia and psychiatric comorbidity for PLWD, symptoms of burnout and psychiatric comorbidity for caregivers, as well as wellbeing and quality of life levels for both.

On the other hand, ICT4Life platform provides solutions for integrating sensors, cameras and Kinect for recognizing the patient's activity and detecting deviations from persons' daily conduct. Additionally, the platform makes available the use of unobtrusive biomedical sensors for continuous monitoring of the patient's health status.

Finally, both platforms, track and analyse the patient access to the different interfaces of the platforms building the digital profile and behavior of each user. Then, patient's health status, activity and digital behavior are screened to the professionals using an advanced visual analytics tool designed to provide information about the patient's medical and social status.

\section{TECHNOLOGY AND ARCHITECTURES}

The goal of this section is to provide a high-level overview of the architectures of the C-MMD and ICT4LIFE platforms. We will describe the main components of both the systems and the main interactions among their internal components.

In C-MMD (Figure 1) there are decoupled services running in parallel to the social networking platform developed to support the mutual assistance community related to dementia. The data storage is performed by an open-source relational database management system (RDBMS) and uses MongoDB ${ }^{3}$ to store data in JSON-like documents, which can vary in structure.

C-MMD main platform was developed using the Ruby on Rails ${ }^{4}$ web development framework and makes use of a Git source control to encourage distant developers to maintain multiple local independent branches and a merging and deploying protocol. React library ${ }^{5}$ was used for building the user interfaces, Redux ${ }^{6}$ to emit state updates in response to actions and Twitter Bootstrap was used as a front-end framework.

\footnotetext{
https://www.mongodb.com

4 http://rubyonrails.org/

5 https://reactjs.org

${ }^{6} \mathrm{http}: / /$ redux.js.org
} 


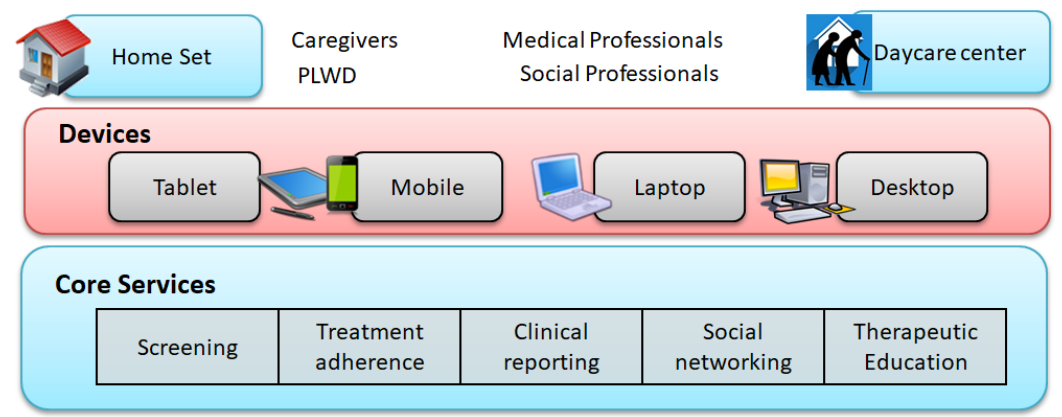

Enabling Services
\begin{tabular}{|c|c|}
\hline Machine Learning & Internationalization and localization \\
\hline Gamification and Serious games & Personalization and UI Adaptation \\
\hline Non-pharmacological interventions & Account management \\
\hline
\end{tabular}

Data Repositories
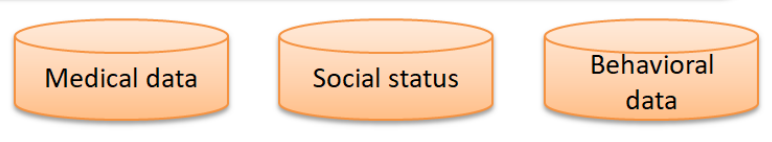

Figure 1: C-MMD Platform Overview

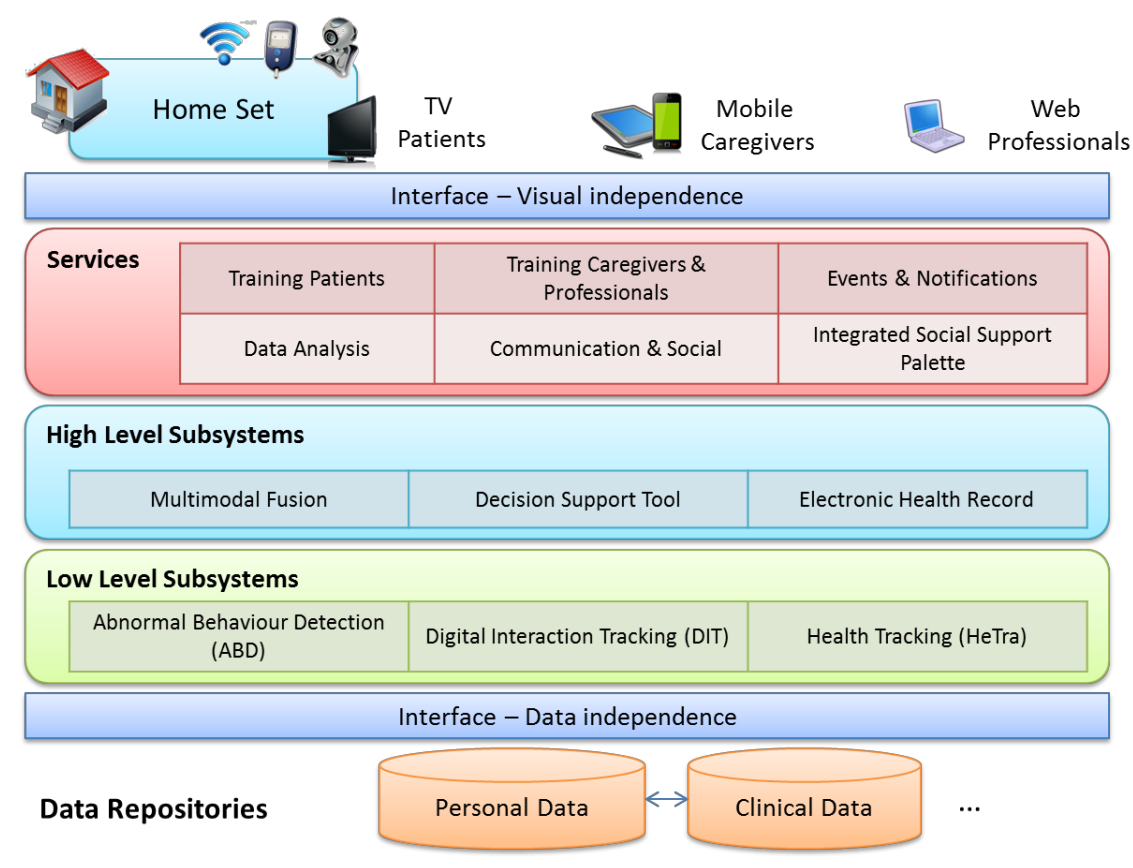

Figure 2: ICT4Life Platform Overview 
Table 2: Intervention types implemented in the two projects of the study

\begin{tabular}{|c|c|c|c|}
\hline & \multicolumn{2}{|c|}{ ICT4Life } & C-MMD \\
\hline Information & \multicolumn{2}{|c|}{ Sensor based abnormal event detection } & Information and adjustment to diagnosis \\
\hline $\begin{array}{l}\text { Management / } \\
\text { identification } \\
\text { of symptoms }\end{array}$ & $\begin{array}{l}\text { Alzheimer patients } \\
\text { - Daily Motion } \\
\text { - Dream (Night Motion) } \\
\text { - Patient Disoriented } \\
\text { /Confusion/ Wandering } \\
\text { - Sign of Apathy } \\
\text { - Number of visits to the } \\
\text { bathroom } \\
\text { - Patient disoriented and } \\
\text { leaving the house }\end{array}$ & $\begin{array}{l}\text { Parkinson patients } \\
\text { - Fall down } \\
\text { - Freezing } \\
\text { - Festination } \\
\text { - Loss of balance } \\
\text { - Movement evolution }\end{array}$ & $\begin{array}{l}\text { - Stress } \\
\text { - Anxiety } \\
\text { - Depression } \\
\text { - Dementia symptoms }\end{array}$ \\
\hline $\begin{array}{l}\text { Cognitive } \\
\text { functioning }\end{array}$ & $\begin{array}{l}\text { Emphasis on continuous } \\
\text { abnormal behaviors }\end{array}$ & ser monitoring to identify & $\begin{array}{l}\text { Emphasis on non-pharmacological interventions for } \\
\text { improving and maintaining cognitive functioning }\end{array}$ \\
\hline Quality of life & $\begin{array}{l}\text { - Patient independence and } \\
\text { - Remote, continuous and } \\
\text { physical and cognitive hea }\end{array}$ & $\begin{array}{l}\text { utonomy at home } \\
\text { ccurate monitoring of both } \\
\text { th }\end{array}$ & $\begin{array}{l}\text { - Patient independence and autonomy at home } \\
\text { - Mental health and quality of life for both members of } \\
\text { the dyad }\end{array}$ \\
\hline
\end{tabular}

Other C-MMD platform components and peripherals were created with HTML5 based development frameworks and Java for delivering RESTful application program interface (API) that uses HTTP requests to handle data in JavaScript Object Notation (JSON) format.

The sensors that are used in ICT4Life platform (Figure 2) are: Kinect camera, Zenith (360o) camera, Microsoft Band 2, UPM7 Band, Hexiwear Band and a Wireless Sensor Network. The acquired data are saved in a non-relational database (MongoDB) which are then processed from the Abnormal Behaviour Detection modules. A cloud-distributed server (Amazon Web Services AWS) is used in order to host all services that ICT4Life provides. ICT4Life services are implemented as a set of independent micro application approach where each micro-application runs independently and exposes an independent REST layer for connectivity. Data warehouse of ICT4Life is with different kind of databases depending on the nature of the data to be stored. ICT4Life platform includes two instances of MongoDB for partitioning and sharing purposes. These instances take care of replicas and failover procedures included in order to prevent data loss and guarantee data availability. A relational database enhanced by Amazon $\mathrm{RDS}^{8}$, which is a regular MySQL ${ }^{9}$ database but with an upper layer for easing configuration, utilization and scalability of the database. Amazon RDS takes the responsibility for administrating tasks that usually consumes a lot of time such as: backups, software updates or patches, escalation and

\footnotetext{
${ }^{7}$ Band prototype created by Universidad Politecnica de Madrid

${ }^{8} \mathrm{https}: / /$ aws.amazon.com/rds/

${ }^{9}$ https://www.mysql.com/
}

replication. Furthermore, Amazon S3 storage $^{10}$ is used for large contents. Finally, Redis ${ }^{11}$ database, which is an open source database in memory, is used for notifications and cache purposes.

\section{Discussion}

C-MMD followed non-pharmacological interventions which consisted of a range of approaches focusing on quality of life improvement, conceived as a combination of quality of life conditions, of satisfaction with life conditions and of personal values, aspirations (preferences) and expectation [7].

ICT4Life, estimates the mental and physical status of the patient giving significant information to the medical professionals regarding their condition.

Interventions are of special interest for both projects (Table 2). In C-MMD understanding Dementia topics like symptomatology \& diagnosis, medication, physical \& behaviour changes, getting help and "looking after myself" topics were given first priority. Other side topics like relationships (friends \& family) and planning for the future were supported as well. A taxonomy of interventions was proposed inline with the "A Guide to Psychosocial Interventions in Early Stages of Dementia" booklet written by The British Psychological Society [8].

ICT4Life does not directly intervene, but the medical professional or physiotherapist can modify the medical treatment or the rehabilitation exercises based on the outcomes of the patient monitoring and behavior analysis.

\footnotetext{
${ }_{11}^{10}$ https://aws.amazon.com/s3/

11 https://redis.io/
} 


\section{CONCLUSIONS}

ICT4LIFE and C-MMD projects give emphasis on nonpharmacological interventions for delivering treatment to people with cognitive impairments and their caregivers, an approach for which preliminary evidence that can improve the quality of life of persons with dementia living at home was found by other researches as well [9]. Both projects highlight the need of addedvalue services such as Serious Games (e.g. cognitive training games), computer-mediated communication within all user groups, social network services and the offer of valid scientific content.

Apart from the above, C-MMD gives more emphasis on interventions, which include a classification of nonpharmacological interventions, such as articles to educate caregivers and PLWD, information about the progress of disease, Serious Games and solutions for independent living. The sensing component of C-MMD is purely software, namely the interaction of the dyads with the platform, as well as the use of neuropsychological assessment batteries and quality of life questionnaires. End-users of the C-MMD can seek for advice mainly coming from the community itself by sharing their common problems and everyday life experiences. In parallel, medical and social professionals share scientifically valid articles to support the community.

On the other hand, ICT4Life, besides the user interaction with the system, makes use of passive sensors for patient activity detection and analysis enabling the automatic assessment of his/her status based on number, duration and frequency of the abnormal incidents. The system is capable of notifying the caregiver via a real-time alert in the case of dangerous event of the patient (such as fall, leaving the house etc.). Finally, ICT4Life platform allows the direct one-to-one communication between patients, caregivers and medical professionals exchanging valuable information related to the patient health status and quality of life.

Potentially, both projects can be benefited from each other by exchanging platform design requirements, anonymized results of their pilot studies and gamification elements.

\section{ACKNOWLEDGMENTS}

This work was partially supported by the European Union' Horizon 2020 Research and Innovation Programme under Grant Agreements No 690090 for ICT4Life and No 690211 for CAREGIVERSPRO-MMD project.

\section{REFERENCES}

[1] H. G. van der Roest, F. J. M. Meiland, C. Jonker, and R. M. Dröes. 2010. User evaluation of the DEMentia-specific Digital Interactive Social Chart (DEMDISC). A pilot study among informal carers on its impact, user friendliness and, usefulness. Aging \& Mental Health, 14(4), 461-470.

[2] M. Torkamani, L. McDonal, I. Saez Aguayo, C. Kanios, M. N. Katsanou, L. Madele, et al. 2014. A randomized controlled pilot study to evaluate a technology platform for the assisted living of people with dementia and their carers. Journal of Alzheimer's Disease, 41(2), 515-23.

[3] J. Wenborn, S. Hynes, T. Swinson, R. Ledgerd, S. Rooks and M. Orrell, 2013. Valuing active life in dementia (VALID): community occupational therapy in dementia. BRITISH JOURNAL OF OCCUPATIONAL THERAPY, 76, 2-3.
[4] A. Kurz, C. Bakker, M. Böhm, J. Diehl-Schmid, B. Dubois, C. Ferreira, et al 2016. RHAPSODY - Internet-based support for caregivers of people with young onset dementia: Program design and methods of a pilot study. International Psychogeriatrics, 28(12), 2091-2099. doi:10.1017/ S1041610216001186.

[5] L. Kerpershoek, M. de Vugt, C. Wolfs, H. Jelley, M. Orrell, R. Woods, et al. 2016. Access to timely formal dementia care in Europe: Protocol of the Actifcare (Access to Timely Formal Care) Study. BMC Health Services Research, 16(1), 423. doi: 10.1186/s12913-016-1672-3.

[6] I. Kostavelis, A. Kargakos, D. Giakoumis, and D. Tzovaras 2017. Robot's Workspace Enhancement with Dynamic Human Presence for Socially-aware Navigation". In $11^{\text {th }}$ International Conference on Computer Vision Systems (ICVS 2017), Shenzhen, China, Jul 2017.

[7] D. Felce, and Perry J. 1995. Quality of life: Its definition and measurement. Research in Developmental Disabilities, 16(1), 51-74.

[8] BPS. 2014. A Guide to Psychosocial Interventions in Early Stages of Dementia, The British Psychological Society.

[9] C. Cooper, N. Mukadam, C. Katona, C. G. Lyketsos, D. Ames, P. Rabins, et al., 2012. Systematic review of the effectiveness of nonpharmacological interventions to improve quality of life of people with dementia. International Psychogeriatrics, 24(6), pp.856-870. 